\title{
Gastric subepitelyal lezyonlar: Endoskopik ultrasonografi'nin yeri ve etkinliği
}

\section{Gastric subepithelial lesions: place and effectiveness of endoscopic ultrasonography}

\section{(D) Nurettin TUNÇ ${ }^{1}$, (D) Mehmet YALNIZ², (D) Ibrahim Halil BAHÇECIOĞLU², (D) Ulvi DEMIREL ${ }^{2}$}

Sağlık Bilimleri Üniversitesi, Diyarbakır Gazi Yaşargil Eğitim ve Araştırma Hastanesi, ${ }^{1}$ Gastroenteroloji Kliniği, Diyarbakır

Furat Üniversitesi Tip Fakültesi, ${ }^{2}{ }_{\zeta ̧}$ Hastalıları Anabilim Dah, Gastroenteroloji Bilim Dalı, Elazığ

Giriş ve Amaç: Üst gastrointestinal sistem endoskopisinde saptanan subepitelyal kitlelerin sıklığ ve bu lezyonlarda endoskopik ultrasonografinin ektinliğini saptamayı amaçladık. Gereç ve Yöntem: Fırat Üniversitesi Tıp Fakültesi Hastanesi Gastroenteroloji Kliniğinde Aralık 2012-Mayıs 2017 tarihleri arasinda üst gastrointestinal sistem endoskopik incelemesinde subepitelyal lezyon saptanip lineer endoskopik ultrasonografi yapılan hastalar retrospektif olarak incelendi. Hastalarn yaş, cinsiyet gibi demografik verileri, üst gastrointestinal sistem endoskopide tanımlanan lezyonlar ve yerlessim yerleri, ince iğne aspirasyon sitolojisi sonuçlarn retrospektif olarak incelendi. Lezyonun boyutu, yapısı, köken aldığı duvar katı, çevre doku ile ilişkisi değerlendirildi. Bulgular: Toplam 14030 üst gastrointestinal sistem endoskopi'den 64 vakada (\%0.45) subepitelyal lezyon saptandı. Yaş ortalaması 53.44 (minmaks: 25-79) yıl idi. Cinsiyetler arasında benign malign ayırımında istatistiksel fark yoktu $(p=0.58)$. Malign olan vakaların ortalama boyutu $34.6 \pm 16.57$ $\mathrm{mm}$, benign olanlarin boyutu $14.39 \pm 7.97 \mathrm{~mm}$ idi $(p=0.001$ ). Subepitelyal lezyonların 33'ü (\%51.6) antrum, 18'i (\%28.1) korpus, 9'u(\%14.1) kardiya 2'si (\%3.1) fundus ve 2'si (\%3.1) tüm midede yaygın lezyonlar olarak raporlanmıştı. Lezyonların 13'ünde (\%20.3) mide katmanı belirtilmemiş, 45'inde (\%70.3) belirtilmiş, 6'sında (\%9.3) dış bası olarak raporlanmıştı. Mide katmanı belirtilenlerden 6'sı (\%9.4) mukoza, 8'i (\%12.5) muskularis mukoza, 23'ü (\%35.9) submukoza, 7'si (\%10.9) muskularis propria, l'i (\%1.6) seroza kaynaklı idi. Endoskopik ultrasonografi - ince iğne aspirasyon biyopsisi 64 vakanın 26'sında (\%40.6) uyguland1. Bu 26 vakanın 3'ünde (\%11.5) materyal yetersiz, 23'ünde (\%88.5) yeterli idi. Biyopsi alınanların 19'u (\%73.1) benign, 5'i (\% 19.2) malign veya malignite şüphesi (yetersiz materyal olanlardan 1 vaka benign) olarak raporlanmıştı. Malign benign ayırımında boyut dışında yaş, cinsiyet, subepitelyal lezyonun kaynaklandığı mide kısmı ve katmanı arasında istatistiksel anlamlı bir ilişki saptanmadı. Sonuç: Endoskopik ultrasonografi biyopsi ile benign-malign ayırımında üstün tanısal katkılar sunduğundan üst gastrointestinal sistem endoskopisi esnasinda saptanan subepitelyal lezyonların ileri tetkiklerinde ilk yapılacak yöntem olmalıdır.

Anahtar kelimeler: Subepitelyal lezyon, endoskopik ultrasonografi, etkinlik
Background and Aima: To determine the frequency of subepithelial masses detected during upper gastrointestinal endoscopy and the efficacy of endosonography in these lesions. Material and method: This study included patients who underwent endosonography for a subepithelial lesion at Firat University Medical Faculty Hospital Gastroenterology Clinic between December 2012 and May 2017. Demographic data, such as age and gender of patients, were analyzed. The size and location of the lesions identified on upper GIS endoscopy were obtained. The endosonographic examination evaluated the size, structure, and wall layers of the lesion. Fine needle aspiration cytology results were evaluated retrospectively. Results: Subepithelial lesions were detected in 64 cases (0.45\%) among 14030 upper gastrointestinal system endoscopy cases. The mean age was 53.44 years (range: $25-79$ ) years. No statistical difference was observed between the sexes regarding the differentiation of benign malignancies ( $p=0.58$ ). The mean size of the malignant cases was $34.6 \pm 16.57 \mathrm{~mm}$, and the size of the benign cases was $14.39 \pm 7.97$ $\mathrm{mm}(p=0.001)$. The location of the subepithelial lesions was antrum 33 (51.6\%), corpus 18 (28.1\%), cardia 9 (14.1\%), fundus $2(3.1 \%)$, and 2 (3.1\%) cases with widespread lesions in the entire stomach. Of the 45 cases, 6 (9.4\%) were mucosa, 8 (12.5\%) muscularis mucosa, 23 (35.9\%) submucosa, 7 (10.9\%) muscularis propria, 1 (1.6\%) was serosa, and $6(9.4 \%)$ were external compression. Of the $26(40.6 \%)$ cases who underwent endosonography-guided fine needle aspiration biopsy, 3 (11.5\%) were insufficient, and 23 (88.5\%) were sufficient. Biopsy results of these cases were reported as benign in 19 (73.1\%) and malignant or suspected malignancy in 5 (19.2\%) cases. No statistically significant relationship was observed between age, sex, subepithelial lesion originating from gastric organs and layers. Conclusion: Endoscopic ultrasonography can contribute to the diagnosis and differentiation of between benign and malignant lesions through biopsy. Therefore, it should be the preliminary method to evaluate further the subepithelial lesions detected during upper gastrointestinal endoscopy.

Keywords: Subepithelial lesion, endoscopic ultrasonography, efficiency

\section{GIIRIŞ}

Gastrointestinal sistemin subepitelyal lezyonu (SEL), üzeri normal mukoza ile kaphı lümen içine doğru büyüyen bir lezyon, kitle veya çıkıntı olarak tanımlanır (1). Genellikle asemptomatiktirler ancak nadiren kanama, obstrüksiyon, disfaji gibi semptomlara neden olurlar (1). Rutin endoskopilerde SEL prevalansının \%0.36 olduğu tahmin edilmektedir (2). Tarama amaçlı endoskopilerin yaygın kullanılması nedeniyle subepitelyal lezyonların tanısı artmaktadır (3).

SEL'lerde endoskopik biyopsiler tanısal olmamaktadır (4). Endoskopik incelemede insidental olarak saptanan SEL'lerin değerlendirilmesi ve sinıflandırılması zordur. Bu nedenle ek görüntüleme yöntemlerine başvurulur. Kesin tanı amacıyla kontrastlı görüntülemeler (bilgisayarlı tomografi, manyetik rezonans görüntüleme) ve endoskopik ultrasonografi (EUS) kullanılmaktadır. Gastrointestinal duvarın beş katlı bir yapısı tanımlandıktan sonra SEL'lerin tanısı ve onların gastrointes-

İletişim: Nurettin TUNÇ Sağlık Bilimleri Üniversitesi, Diyarbakır Gazi Yaşargil Eğitim ve Araştırma Hastanesi, ${ }^{1}$ Gastroenteroloji Kliniği, Diyarbakır • E-mail: nurettin@ firat.edu.tr Tel: +90 4122580060 • Fax: +90412258013 Geliş Tarihi: 26.11.2019 Kabul Tarihi: 09.12.2019 
tinal sistem (GIS) duvar katman invazyonu saptanabilir hale gelmiştir (5). EUS, gastrointestinal kanalın içini, çevresini değerlendirmek ve tanısal amaçlı kullanıldığında, ince aspirasyon iğneleri ile GISS lümenin duvarında yerleşmiş subepitelyal lezyonlardan doku ve sıvı örnekleri alınabilmektedir (6). EUS eşliğinde ince iğne aspirasyon biyopsisi (EUS-İAB) yapılarak SEL'lerden daha derin biyopsi alınabilmektedir. SEL'lerde EUS-İAB uygulamasının farklı submukozal tümörlerin ayırıcı tanısında yararlı olduğu gösterilmiştir (4). EUS-İ̇AB farklı lezyonların sitopatolojik tanısında \%83 gibi yüksek oranlarda başarı sağlamaktadır (7). SEL'ler ve kaynaklandığı katmanlar Tablo l'de gösterilmiştir (8).

Gastrointestinal duvar düşük frekansh (7.5-12 MHz) beş katmanlı bir yapı ve yüksek frekansh (12-20 MHz) dokuz katmanlı bir yapı olarak algılanır (8).

Submukozal lezyonlardan lipom ve leiymiyomlar benign seyirli oldukları için takip edilebilirler (9). Gastrointestinal stromal tümörler (GIST'ler) malign potensiyele sahip oldukları için (7), nöroendokrin tümörler (NET) genel olarak agresif seyirli olduğundan (10) cerrahi tedavi önerilmektedir. Cerrahi veya takip kararı verilirken bazen patolojik örnekleme ve doku tanısı istenebilmektedir (7).

\section{GEREC ve YÖNTEM}

Bu çalışmada Fırat Üniversitesi Tıp Fakültesi Hastanesi Gastroenteroloji Kliniğinde Aralık 2012- Mayıs 2017 tarihleri arasinda üst GIS endoskopik incelemesinde subepitelyal lezyon saptanıp lineer EUS (Pentax UG 360 lineer endoscopy plus Hitachi EUB 7500 US, Tokyo, Japan) yapilan hastalar retrospektif olarak incelendi. Tüm hastalara lineer EUS 2-5 mg midazolam ile sedasyon altında 12 saatlik açlı̆̆ takiben aynı uzman tarafından yapılmıştı. Hastaların yaş, cinsiyet gibi demografik verileri, üst GIS endoskopide tanımlanan lezyonlar ve yerleşim yerleri, EUS ile elde edilen bulgular, EUS ince iğne aspirasyon sitolojisi (AS) yapılmış ise patoloji sonuçları retrospektif olarak incelendi. Üst GIS endoskopide tanımlanan alanda subepitelyal lezyon eko-endoskop ile endoskopik olarak saptandı ise lezyonun sayısı, en büyük boyutu, yapısı (hipo-hiperekojen homojen-heterojen), köken aldığı duvar katı (mukoza-muskularis mukoza-submukoza- muskularis propria-seroza), lezyonun boyutları, çevre doku ile ilişkisi değerlendirildi. Tanımlanan alanda endosonografik olarak çevre doku ve organlardan köken alan lezyon izlendi ise lezyonun yapısı, köken aldığı doku, gastrointestinal duvar ile ilişkisi belirlendi.

Saplı polipoid lezyon, önceden üst GIS malignitesi olan ya da malignite nedeniyle operasyon geçiren hastalar çalışmaya alınmadi.

\section{İstatistiksel Analiz}

Tüm verilerin istatiksel analizi SPSS 22.00 paket programı kullanılarak yapıldı. Sonuçlar kategorik değişkenler için yüzde, sürekli değişkenler için ortalama standart sapma veya ortanca (minimum-maksimum) olarak sunuldu. Grup oranlarının karşılaştırılmasında ki kare ve Fisher's exact test kullanıldı. Grup ortalamalarının karşılaştırılmasında normal dağılım gösteren değişkenler için Student t testi, normal dağılım göstermeyen değişkenler için Mann-Whitney U ile Wilcoxon işaret testleri kullanıldı. İkiden fazla grupta degişkenlerin ortalamaları karşılaştırılırken parametrik değişkenlerde ANOVA yöntemi, non-parametrik değişkenlerde Kruskal Wallis testi kullanıldı.

\section{BULGULAR}

Toplam 14030 üst GIS endoskopisinden 64 vakada (\%0.45) SEL saptandı. Çalışmaya yaş ortalaması 53.44 (min-maks: 25-79) yll olan 27'si (\%42.2) kadın 37'si (\%57.8) erkek toplam 64 vaka dahil edildi. Cinsiyetler arasında benign malign ayırıminda istatistiksel fark yoktu $(\mathrm{p}=0.58)$.

Tablo 1. Gastrik SEL'lerin karakteristik özellikleri: Birinci katman (lümen sıvısının ve mukozanın ara yüzü), ikinci katman (muskularis mukoza), üçüncü katman (submukoza), dördüncü katman (muscularis propria) ve beşinci katman (seroza veya adventisya) $(1,8)$.

Lezyon Tipi
GIST
Leiyomiyom
Lipom
Varis
Schwannom
Inflamatuvar fibroid polip
Ektopik pankreas
Karsinoid
Granüler hücreli tümör
NET

\section{EUS Katmanı}

Dördüncü (nadiren ikinci)

Ikinci ve dördüncü

Üçüncü

Üçüncü

Dördüncü

Ikinci ve/veya üçüncü

Ikinci veya üçüncü ve/veya dördüncü

Ilkinci ve/veya üçüncü

Ikinci veya üçüncü

\author{
Karakteri \\ Malign potansiyel \\ Benign \\ Benign \\ Benign \\ Benign \\ Benign \\ Benign \\ Malign potansiyel \\ Benign \\ Malign potansiyel
}

SEL: Subepitelyal lezyon, EUS: Endoskopik ultrasonografi, GIST: Gastrointestinal stromal tümör, NET: Nöroendokrin tümör. 
SEL boyutları ortalama 18.05 mm (min-maks: 3-55) idi. Malign olan vakalarm ortalama boyutu $34.6 \pm 16.57 \mathrm{~mm}$, benign olanların boyutu $14.39 \pm 7.97 \mathrm{~mm}$ idi $(\mathrm{p}=0.001)$.

Subepitelyal lezyonların 33'ü (\%51.6) antrum, 18'i (\%28.1) korpus, 9'u(\%14.1) kardiya, 2'si (\%3.1) fundus, 2'si (\%3.1) tüm midede yaygın lezyonlar olarak raporlanmıştı (Tablo 2). SEL'lerin çoğu antrumda lokalize idi ( $p=0.67)$. Benign ve malign lezyonların midede dağılımları Tablo 3'te gösterilmiştir.

Kırk beş (\%70.3) vakada lezyonların kaynaklandığı mide katmanı belirtilmiştir. Toplam 64 vakanın 6'sı (\%9.4) mukoza, 8'i (\%12.5) muskularis mukoza, 23'ü (\%35.9) submukoza, 7'si (\% 10.9) muskularis propria, 1'i (\%1.6) seroza kaynaklı ve 6'sı (\%9.4) dış bası idi (Tablo 2). Vakaların çoğu submukoza kökenli idi $(\mathrm{p}=0.72)$. Benign ve malign SEL'lerin kaynaklandığı mide katmanları Tablo 3'te özetlenmiştir.

EUS ile vakaların 7'sinde (\% 12.5) lezyon saptanmamış, 16'sı (\%25.0) leiyomiyom, 13'ü (\%20.3) lipom, 7'si (\%10.9) GIST, 6’sı (\%9.4) dış bası, 3’ü (\%4.7) ektopik pankreas, 3'ü mukozal kalınlaşma (\%4.7), l'i (\%1.6) lenfoma, l'i (\%1.6) NET, l'i (\%1.6) kitle tanısıyla raporlanmıştı.

Tablo 2. EUS yapılan hastaların genel özellikleri, ( $p<0.05$ anlamlı olarak ifade edilmiştir).

\begin{tabular}{|c|c|c|c|}
\hline Özellik & & n (\%) & p değeri \\
\hline Cinsiyet n (\%) & $\begin{array}{l}\text { Kadın } \\
\text { Erkek }\end{array}$ & $\begin{array}{l}27(\% 42.2) \\
37(\% 57.8)\end{array}$ & $\mathrm{p}=0.58$ \\
\hline Kaynaklandığı mide bölümü n (\%) & $\begin{array}{l}\text { Antrum } \\
\text { Korpus } \\
\text { Fundus } \\
\text { Kardiya } \\
\text { Yaygın }\end{array}$ & $\begin{array}{l}33(51.6) \\
18(28.1) \\
2(3.1) \\
9(14.1) \\
2(3.1)\end{array}$ & $\mathrm{p}>0.067$ \\
\hline Kaynaklandığı mide katmanı n (\%) & $\begin{array}{l}\text { Mukoza } \\
\text { Muskülaris mukoza } \\
\text { Submukoza } \\
\text { Muskülaris propria } \\
\text { Seroza } \\
\text { Diss bası } \\
\text { Belirtilmeyen }\end{array}$ & $\begin{array}{l}6(9.4) \\
8(12.5) \\
23(35.9) \\
7(10.9) \\
1(1.6) \\
6(9.4) \\
13(20.3)\end{array}$ & $\mathrm{p}>0.22$ \\
\hline EUS-İIAB n (\%) & $\begin{array}{l}\text { Alınmayan } \\
\text { Alınan } \\
\text { Benign } \\
\text { Malign } \\
\text { Malignite şüphesi } \\
\text { GIST } \\
\text { NET } \\
\text { Soliter fibröz adenom } \\
\text { Adenomatöz polip }\end{array}$ & $\begin{aligned} 38 & (59.4) \\
26 & (40.6) \\
19 & (73.1) \\
1 & (3.8) \\
1 & (3.8) \\
2 & (7.7) \\
1 & (3.8) \\
1 & (3.8) \\
1 & (3.8\end{aligned}$ & \\
\hline Boyut mm (ortalama \pm std sapma) & $\begin{array}{l}\text { Benign } \\
\text { Malign veya şüphesi }\end{array}$ & $\begin{array}{l}15.13 \pm 7.46 \\
34.6 \pm 16.7\end{array}$ & $\mathrm{p}=\mathbf{0 . 0 0 1}$ \\
\hline
\end{tabular}

EUS: Endoskopik ultrasonografi, EUS-IIAB: Ince iğne aspirasyon biyopsisi, GIST: Gastrointestinal stromal tümör, NET: Nöroendokrin tümör.

Tablo 3. EUS-İIAB benign-malign SEL'lerin yerleşim yerlerinin karşılaştırılması

\begin{tabular}{lllll}
\hline \multirow{2}{*}{ Mide kismı } & Benign n (\%) & Malign n (\%) & Toplam n (\%) & \\
& Antrum & $12(\% 57.1)$ & 0 & $12(\% 46.2)$ \\
& Korpus & $5(\% 23.8)$ & $3(\% 60)$ & $1 \% 30.8)$ \\
& Fundus & $1(\% 4.8)$ & 0 & $3(\% 3.8)$ \\
\multirow{3}{*}{ Mide katmanı } & Kardiya & $2(\% 9.5)$ & $1(\% 20)$ & $2(\% 7.7)$ \\
& Pangastrik & $1(\% 4.8)$ & $1(\% 20)$ & $2(\% 7.7)$ \\
& Mukoza & $2(\% 9.5)$ & 0 & $4(\% 15.4)$ \\
& Mukularis mukoza & $4(\% 19.0)$ & 0 & $9(\% 34.6)$ \\
& Submukoza & $9(\% 42.9)$ & 0 & $5(\% 19.2)$ \\
& Muskularis propria & $3(\% 14.3)$ & $2(\% 40)$ & $1(\% 3.8)$ \\
& Seroza & 0 & $1(\% 20)$ & $5(\% 19.2)$
\end{tabular}

SEL: Subepitelyal lezyon, EUS-IIAB: Ince iğne aspirasyon biyopsisi. 
EUS-IIAB 26 vakada (\%40.6) uygulanmıștı. Biyopsi uygulanan vakaların 3'ünde (\%11.5) materyal yetersiz, 23'ünde (\%88.5) yeterli idi. Bu vakaların biyopsi sonuçları 19 (\%73.1) benign, 1 (\%3.8) malign, 1 (\%3.8) malignite şüphesi, 1 (\%3.8) soliter fibröz adenom, 1 (\%3.8) adenomatöz polip, 1 (\%3.8)NET, 2 (\%7.7) GIST olarak raporlanmıştı. Toplam 5 (\%19.2) vaka malign olarak raporlanmıştı (Tablo 2).

Malign benign ayırımında boyut dışında, yaş, cinsiyet, SEL'in kaynaklandığı mide kısmı ve katmanı arasında istatistiksel anlamlı bir ilişki saptanmadı.

\section{TARTIŞMA}

Üst GIS endoskopi esnasında saptanan SEL'lerin endoskopik olarak benign malign ayırımı yapılamamaktadır ve standart endoskopik biyopsiler tanısal olmamaktadır. EUS SEL'lerin özelliklerinin tanımlanması ve IIAB ile daha derin biyopsi alınabilmesine olanak sağlar, böylece submukozal tümörlerin ayırıcı tanısında yararlı olduğu bildirilmiştir (4).

Gastrik SEL prevalansı \%0.36 ile \%0.9 arasında raporlanmıştır $(2,11)$. Çalışmamızda gastrik SEL prevalansı \%0.45 ile literatür benzerdi. EUS uygulanan hastaların yaş ortalaması 53.44 (min-maks: 25-79) yll ile literatür ile benzerdi (11).

Yapılan çalışmalarda üst GIS endoskopisinde saptanan SEL'lerin EUS ile saptanma oranları \%89 (12) ve \%77 olarak belirtilmişti. Bizim çalışmamızda da benzer şekilde \%12.5 vakada lezyon saptanmamış ve lezyon saptama oranı \%87.5 ile literatür ile uyumlu idi. Bu lezyonların saptanamamış olması muhtemelen lineer EUS kullanıyor olmamız, lezyonların EUS ile görülemeyecek kadar küçük olması veya endoskopide mide hava şişirilmesi nedeniyle karaciğer, dalak, safra kesesi gibi dış basıların EUS ile (mide hava aspire edildiğinden) görülmemesi olabilir.

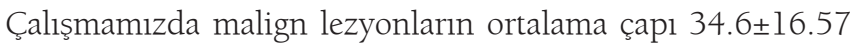

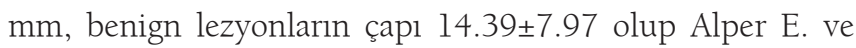
arkadaşlarının çalışması (11) ile uyumlu olarak anlamlı idi ( $p=0.001$ ). Malignite riski boyut artışı ile artmaktadır. Boyutu 30 mm'yi aşan lezyonlar EUS ile yakın takip edilmeli ve malignite ayırımı için EUS-İAB açısından değerlendirilmelidir.

EUS-İAB ile malign olan 5 vakanın 2'si malign veya malign şüphesi, 2'si GIST ve 1'i NET olarak raporlanmıştı, malignite şüphesi olan bir vakanın da postoperatif patolojisi NET olarak raporlanmıştı. GIST'lerin büyük çoğunluğu midede saptanmaktadır (13). Mide GIST'lerinin çoğunda tümörlerin korpusta (\%68) vekardiya-fundus (\%20) yerleşimli olduğu saptanmış (14). Bizim çalışmamızda da literatürle benzer şekilde iki GIST vakasından biri korpus diğeri kardiyada lokalize idi. Vakalarımızdan biri $30 \mathrm{~mm}$ diğeri $46 \mathrm{~mm}$ boyutunda izlenmiş olup cerrahi önerilmişti. Günümüzde NET'ler; G1 (eski adı: karsinoid tümör), G2 ve G3 (nöroendokrin karsinomu; NEC) olarak sinıflandırılır. NET'ler sıklıkla 40-50 yaş arasında görülür ve cinsiyet oranı (M/F) 2/l'dir (15). Bizim iki vakamız da erkek cinsiyetti. Biri 43, diğeri 79 yaşında olup literatürden farklı izlendi. National Comprehensive Cancer Network (NCCN) klavuzuna göre, tip I ve II G-NET'in yönetimi, büyüklüğü 20 mm'den küçük olan ve tümör sayısından bağımsız olarak muskularis propriayı invaze etmeyen veya metastazı olmayan tümörler için basit gözetim veya endoskopik rezeksiyondur (ER). Tek veya çoklu olsun, > 20 mm'den büyük tümörler için cerrahi rezeksiyon veya ER önerilir. Tip III G-NET için, endoskopik veya kama rezeksiyonu için düşünülebilecek 2 cm'den küçük tümörler dışında, gastrik karsinomlarla aynı şekilde yönetilmesi önerilir (16). Vakalarımızdan biri büyüğü $12 \mathrm{~mm}$ boyutunda multiple Gl olarak değerlendirilmiş takip programına alınmış, diğeri $30 \mathrm{~mm}$ boyutunda olup cerrahi eksizyon önerilmişti.

Alman endoskopik ultrasonografi kayıtlarında en sık izlenen benign mide subepitelyal lezyon leiyomiyom (\%23.7) ve ektopik pankreas (\%23.2) idi (17). Bizim çalışmamızda lezyonların 16'sı (\%25.0) leiyomiyom olup en çok görülen lezyonlardı ve takip önerilmişti. Çalışmamızda vakaların 13'ü (\%20.3) lipom, 3’ü (\%4.7) ektopik pankreas tanısılla raporlanmıştı. Lipomlardan en büyügü $23 \mathrm{~mm}$ çapında olup biyopsi alınanlar benigndi. Lipomlar benign seyirli olduğundan takibe alınmıştı. Ektopik pankreas olan üç olguda (büyüğü 8 mm boyutunda) biyopsi alınmıs, yetersiz olarak raporlanmış, diğerlerine endoskopik diseksiyon önerilmiş ve takip programına alınmıştı. EUS ile ektopik pankreasta \%73.1 özgüllük ve \%58.1 pozitif öngörü değeri gibi nispeten düşük doğrulukta tanı konulmaktadır (18). Ektopik pankreas tanısı bu veriler doğrultusunda sorgulanmalı ve muskularis propriyayı invaze etmemişse endoskopik submukozal rezeksiyon için hasta değerlendirilmelidir (19-21).

Dış bası olan 6 vakanın 2'si dalak, l'i karaciğer, l'i pankreasta kist nedenliydi. Antrum ve kardiyadan kaynaklanan iki vakanın dış bası nedeni belirtilmemişti. Bütün lezyonlar benign karakterde izlenmişti. EUS mide dış basılarının tanımlanmasinda üstün bir yöntem olarak uygulanabilir.

Rektrospektif çalışmalarda olduğu gibi çalışmamızda özellikle vakaların EUS özellikleri olan sınır düzensizliği, hipo-hiperekojenite, homo-heterojenite, biyopsilerin tam elde edilememesi, vakaların başvuru şikayetlerine ulaşılamaması gibi sinirlamalar mevcuttur.

EUS subepitelyal lezyonların görüntülenmesinde, tanının konmasinda en etkin yöntemdir. Biyopsi ile benign-malign ayırımında üstün tanısal katkılar sunduğundan üst GIS endoskopi esnasında saptanan SEL'lerin ileri tetkiklerinde ilk yapılacak yöntem olmalıdır. 


\section{KAYNAKLAR}

1. Gong EJ, Kim DH. Endoscopic ultrasonography in the diagnosis of subepithelial lesions. Clin Endosc 2016;49:425-33.

2. Hedenbro JL, Ekelund M, Wetterberg P. Endoscopic diagnosis of submucosal gastric lesions. The results after routine endoscopy. Surg Endosc 1991;5:20-3.

3. Mohammed Alizadeh AH, Shahrokh S, Hadizadeh M, Padashi M, Zali MR. Diagnostic potency of EUS-guided FNA for the evaluation of pancreatic mass lesions. Endosc Ultrasound 2016;5:30-4.

4. Matsui M, Goto H, Niwa Y, et al. Preliminary results of fine needle aspiration biopsy histology in upper gastrointestinal submucosal tumors. Endoscopy 1998;30:750-5.

5. Aibe T. A Study on the structure of layers of the gastrointestinal wall visualized by means of the ultrasonic endoscope. 1) the structure of layers of the gastric wall. (in Japanese with English abstracts) Gastroenterolocigal Endoscopy 1984;26:1447-64

6. Hawes R, Fockens P. Endosonography. 2002. Second edition. Saunders Elsevier. 27-28

7. Ito $\mathrm{H}$, Inoue $\mathrm{H}$, Ryozawa $\mathrm{S}$, et al. Fine-needle aspiration biopsy and endoscopic ultrasound for pretreatment pathological diagnosis of gastric gastrointestinal stromal tumors. Gastroenterol Res Pract 2012;2012:139083.

8. Kida M, Kawaguchi Y, Miyata E, at al. Endoscopic ultrasonography diagnosis of subepithelial lesions. Dig Endosc 2017;29:431-43.

9. Aydın A, Oruç N, Nart D, Veral A. Endoscopic ultrasound-guided fine-needle aspiration results in upper gastrointestinal system mesenchymal tumors Endoscopy 2016;24:36-42.

10. Dias AR, Azevedo BC, Alban LBV, et al. Gastric neuroendocrine tumor: Review and update. Arq Bras Cir Dig 2017;30:150-54.

11. Alper E, Baydar B, Buyraç Z, et al. Differential diagnosis of submucosal lesions with endosonography. Akademik Gastroenteroloji Dergisi 2011;10:5-8
12. Humphris JL, Jones DB. Subepithelial mass lesions in the upper gastrointestinal tract. J Gastroenterol Hepatol 2008;23:556-66.

13. Steigen SE, Eide TJ. Gastrointestinal stromal tumors (GISTs): a review. APMIS 2009;117:73-86.

14. Oruç N, Aydın A, Tekin F, et al. Comparison of endosonographic and histopathological features of upper GISTs: A single center experience. Endoscopy 2009;17:06-11.

15. Soga J. Gastric carcinoids: A statistic evaluation of 1094 cases collected from the literature. Surg Today 1997;27:893-901.

16. Yamada Y, Kida M, Sakaguchi T, et al. A study on myogenic tumor of the upper gastrointestinal tract by endoscopic ultrasonography. Dig Endosc 1992:4:396-408

17. Gottschalk U, Dietrich CF, Jenssen C. Ectopic pancreas in the upper gastrointestinal tract: Is endosonographic diagnosis reliable? Data from the German Endoscopic Ultrasound Registry and review of the literatüre. Endosc Ultrasound 2018;7:270-8.

18. Seo SW, Hong SJ, Han JP, et al. Accuracy of a scoring system for the differential diagnosis of common gastric subepithelial tumors based on endoscopic ultrasonography. J Dig Dis 2013;14:647-53.

19. He G, Wang J, Chen B, et al. Feasibility of endoscopic submucosal dissection for upper gastrointestinal submucosal tumors treatment and value of endoscopic ultrasonography in pre-operation assess and post-operation follow-up: A prospective study of 224 cases in a single medical center. Surg Endosc 2016;30:4206-13.

20. Zhang Y, Huang Q, Zhu LH, et al. Endoscopic excavation for gastric heterotopic pancreas: An analysis of 42 cases from a tertiary center. Wien Klin Wochenschr 2014;126:509-14.

21. Ryu DY, Kim GH, Park DY, et al. Endoscopic removal of gastric ectopic pancreas: An initial experience with endoscopic submucosal dissection. World J Gastroenterol 2010;16:4589-93. 